\title{
Oestrogen, progesterone, and androgen receptors in ovarian neoplasia: correlation between immunohistochemical and biochemical receptor analyses
}

\author{
Helena C van Doorn, Curt W Burger, Paul van der Valk, Hans M G Bonfrèr
}

\begin{abstract}
Aim-To investigate the correlation between immunohistochemical and biochemical steroid receptor analyses by measurement of oestrogen, progesterone, and androgen receptor status in ovarian neoplasia.
\end{abstract}

Methods-Tissue samples were obtained from 27 ovarian neoplasms, including two borderline tumours. Immunohistochemical staining of the tissue slides was scored semiquantitatively, incorporating the intensity and percentage of positive staining (histoscore). Tumours with a histoscore of 10 or more were considered steroid receptor positive. The epithelial and stromal fractions of the tumours were analysed separately. To study the uniformity of receptor expression throughout a tumour, up to four samples were analysed. Results-Immunohistochemical histoscores of the oestrogen receptor in the epithelial fractions were significantly correlated with the biochemical oestrogen receptor values $(r=0.408)$. Androgen receptor status in the epithelial fraction was correlated with that in the stromal fraction $(r=0.741)$, while androgen receptor histoscores in the epithelial fraction correlated with the biochemical assay values $(r=0.463)$. On biochemical analysis, 17 of the 27 ovarian tumours were oestrogen receptor positive and seven were progesterone receptor positive. On immunohistochemical analysis, eight tumours were oestrogen receptor positive and two were progesterone receptor positive. Biochemical analysis showed that 14 of the 26 tumours were slightly androgen receptor positive (10-50 fmol/mg protein), while all the others were negative. On immunohistochemical analysis, seven of the 26 tumours were androgen receptor positive. When two or more specimens from one tumour were analysed, marked differences in steroid status were found, especially in progesterone receptor and androgen receptor expression. Some parts of a tumour were steroid receptor positive, while other parts were negative owing to heterogeneity of expression.

Conclusions-Immunohistochemical and biochemical analysis of steroid receptors in ovarian tumours correlated weakly or not at all. Heterogeneity of expression within a tumour and the presence of progesterone and androgen receptors in the stromal fraction partly accounted for this observation. Biochemical and immunohistochemical androgen receptor status was much lower than in previous reports.

(F Clin Pathol 2000;53:201-205)

Keywords: steroid receptors; ovarian neoplasia; immunohistochemical analysis; biochemical analysis

Oestrogen, progesterone, and androgen receptors can be studied biochemically and immunohistochemically. Several investigators have found a positive correlation between biochemical and immunohistochemical determination of oestrogen and progesterone receptor status in breast and endometrial carcinoma, ${ }^{1-4}$ while others have not found such a correlation. ${ }^{5}$

Immunohistochemical receptor analysis can be used to examine the representative quality of a tissue sample and to correct for heterogeneity. It can also be applied to tissue samples that are too small for conventional biochemical receptor analysis. ${ }^{6}$ Cellular localisation of steroid receptors in certain neoplasms and the assessment of staining patterns may allow better prediction of their hormone responsiveness in carcinomas. ${ }^{7}$

The major drawback of immunohistochemical receptor analysis in ovarian neoplasia is the lack of standardisation of the scoring system. For breast and endometrial cancer, abundant reports are available on the reproducibility, standardisation, and presence of receptors. ${ }^{89}$ However, only a few studies have compared immunohistochemical and biochemical detection of oestrogen receptors, progesterone receptors, and androgen receptors in ovarian neoplasia. ${ }^{10-12}$ In 17 ovarian carcinomas, Chadha et al could not find a correlation between the density of androgen receptor positive tumour cells or intensity of immunostaining and the results of a biochemical receptor assay, ${ }^{10}$ neither could Kommoss et al find a correlation between immunohistochemical and biochemical oestrogen receptor and progesterone receptor status in ovarian carcinoma. ${ }^{11}$

One explanation for these discrepancies could be that a biochemically false positive receptor status in receptor negative malignant tumours could be caused by benign, receptor positive stromal components. ${ }^{11}$ To address these issues, we performed a comparative study on ovarian tumour tissue samples from a series of 27 patients. In several cases, up to four different 
tisue samples were analysed to assess intratumoral steroid receptor expression. The epithelial and stromal fractions were analysed separately by the immunohistochemical method.

\section{Methods}

SPECIMEN COLLECTION

Tissue samples from epithelial ovarian neoplasms were obtained from 27 patients for immunohistochemical and biochemical analyses of oestrogen receptors, progesterone receptors, and androgen receptors. The participating hospitals were the Free University Hospital Amsterdam, The Netherlands Cancer Institute, Amsterdam, Rijnland Hospital Leiderdorp, Ziekenhuiscentrum Apeldoorn, and Alkmaar Medical Centre. When the tumour was large enough, up to four specimens of around 1 $\mathrm{ml}$ were snap frozen within 30 minutes of surgical removal. Each specimen was divided in two and analysed in two different laboratories. During transport and storage the temperature did not exceed $-20^{\circ} \mathrm{C}$.

BIOCHEMICAL ANALYSIS

All the biochemical analyses were performed at the Netherlands Cancer Institute, within two months of surgery. Oestrogen receptor, progesterone receptor, and androgen receptor analyses were done as described previously. ${ }^{13-15}$ Protein concentrations in the cytosol were determined using Bradford's method, ${ }^{16}$ while the number of binding sites and dissociation constants were determined using Scatchard's method. ${ }^{17}$ Results were expressed in $\mathrm{fmol} / \mathrm{mg}$ protein. Steroid receptor status was classified as negative, slightly positive, and positive (see table 1 for details). Glycerol-stabilised calf uterus homogenate served as control each time the procedure was performed. The laboratories participated in the EORTC receptor study group quality control scheme. ${ }^{18} 19$

IMMUNOHISTOCHEMICAL ANALYSES

These analyses were performed at the end of the study at the Free University Hospital. Freshly cut $4 \mu \mathrm{m}$ cryostat sections were fixed for 10 minutes in buffered formaldehyde, followed by four minutes in methanol $\left(-20^{\circ} \mathrm{C}\right)$ and two minutes in acetone at $-20^{\circ} \mathrm{C}$. The slices were stained according to the instructions on ER-ICA and PgR-ICA kits (Abbott). For androgen receptor analysis, a mouse monoclonal IgG directed against a unique epitope of the N-terminal domain of the human androgen receptor was kindly provided by Professor T H van der Kwast, Dijkzigt Hospital, Rotterdam. This antibody was used in a dilution of 1:100. Immunoreactivity was visualised with diaminobenzidine (Sigma). The sections were counterstained in haematoxylin.

Table 1 Definition of steroid receptor status for biochemical analysis

\begin{tabular}{llll}
\hline & $\begin{array}{l}\text { Oestrogen } \\
\text { receptor }\end{array}$ & $\begin{array}{l}\text { Progesterone } \\
\text { receptor }\end{array}$ & $\begin{array}{l}\text { Androgen } \\
\text { receptor }\end{array}$ \\
\hline Negative & $<6$ & $<10$ & $<10$ \\
Slightly positive & $6-20$ & $10-30$ & $10-50$ \\
Positive & $>20$ & $>30$ & $>50$
\end{tabular}

Amount of receptor expressed in $\mathrm{fmol} / \mathrm{mg}$ protein.
Steroid receptors were evaluated by means of the histoscore. ${ }^{20}$ The percentages of neoplastic cells with positive nuclear staining were classified into five staining intensities: 0 , no staining: nuclei blue; 1, slight staining: nuclei bluebrown; 2, positive staining: nuclei brown; 3, strong staining: nuclei bright brown; 4, very strong staining: nuclei deep brown or black. To obtain the histoscore for each steroid receptor, the sum of these percentages was multiplied by the intensity of staining. The histoscore was considered positive at 10 or higher. By definition the maximum attainable score was 400 .

Positive oestrogen receptor and progesterone receptor controls consisted of positive breast cancer specimens, while positive controls of androgen receptor consisted of prostate tissue. Negative controls were obtained by omission of the second antibody. In the negative control slides, there was no staining of nuclei.

Intraobserver variation was tested by rescoring the specimens after three months. Only minor differences were found, which did not change the tumour status in individual cases; none of the receptor negative tumours scored positive at the second analysis.

\section{STATISTICAL ANALYSIS}

To measure the correlation between the various receptor levels, Pearson's correlation coefficients were calculated. Probability $(p)$ values of 0.05 or lower were considered significant. When more than one sample was analysed the lowest histoscore was employed, together with the mean of the biochemical results.

\section{Results}

Two of the 27 patients had a borderline tumour of the ovary. Of the 25 patients with epithelial malignancies, four had stage I disease, three had stage II, 14 had stage III, and four had stage IV. Histological classification revealed one well differentiated, seven moderately differentiated, and 13 poorly differentiated ovarian carcinomas. In four cases the grade was not specified. Six women with tumour recurrence had been treated with chemotherapy before specimen collection. None of the 23 women older than 50 years had received hormone treatment.

Four specimens could be analysed in nine patients, three in three patients, two in five patients, and one in 10 patients.

Table 2 presents the individual values for the biochemical assays and immunohistochemical analyses of oestrogen receptor, progesterone receptor, and androgen receptor status. For the immunohistochemical analyses, the individual histoscore range is given for both the stromal and epithelial fractions of the tumour. The steroid receptor status of the 27 tumours measured by the two methods is given in table 3 .

Positive immunostaining was observed in the nuclei of the epithelial and stromal cells, in one group of cells or not at all. The proportion of positive cells ranged from $0-90 \%$ and was low in most cases. A positive histoscore was never caused by strong staining of a few cells. 
Table 2 Biochemical and immunohistochemical steroid receptors in ovarian neoplasia $(n=27)$

\begin{tabular}{|c|c|c|c|c|c|c|c|c|c|}
\hline \multirow[b]{2}{*}{ Pt No } & \multicolumn{3}{|c|}{ Oestrogen receptor } & \multicolumn{3}{|c|}{ Progesterone receptor } & \multicolumn{3}{|c|}{ Androgen receptor } \\
\hline & $B C$ & IHC epith & IHC stroma & $B C$ & IHC epith & IHC stroma & $B C$ & IHC epith & IHC stroma \\
\hline 1 & 11 & 20 & 0 & 2 & 0 & 0 & 0 & 0 & 0 \\
\hline 2 & 120 & 90 & 0 & 11 & 0 & 0 & NP & 40 & 0 \\
\hline 3 & 14 & 0 & 0 & 0 & 0 & 0 & 18 & 0 & 0 \\
\hline 4 & 130 & 100 & 0 & 8 & 0 & 0 & 8 & 0 & 0 \\
\hline 5 & 21 & 0 & 0 & 6 & 0 & 0 & 5 & 0 & 0 \\
\hline 6 & 38 & 0 & 0 & 0 & 0 & 0 & 16 & 90 & 0 \\
\hline 7 & 25 & $1-5$ & 0 & 2 & 0 & 0 & 8 & $50-65$ & $5-10$ \\
\hline 8 & 36 & 0 & 0 & 40 & 0 & 0 & 23 & 0 & 0 \\
\hline 9 & 50 & 25 & 0 & 81 & 30 & 85 & 30 & 0 & 0 \\
\hline 10 & 13 & 0 & $0-20$ & 11 & 0 & $10-30$ & 2 & 0 & $10-50$ \\
\hline 11 & 21 & 0 & 0 & 16 & 0 & 0 & 6 & 0 & 0 \\
\hline 12 & 6 & 30 & 0 & 0 & 0 & 0 & 0 & 0 & 0 \\
\hline 13 & 34 & $0-2$ & 0 & 750 & $0-90$ & 0 & 38 & $5-60$ & $0-50$ \\
\hline 14 & 7 & 100 & 0 & 8 & 0 & 0 & 0 & 0 & 0 \\
\hline 15 & 80 & 0 & 1 & 130 & 0 & 80 & 35 & 160 & 80 \\
\hline 16 & 79 & $20-30$ & $0-5$ & 31 & 0 & $0-20$ & 11 & $1-5$ & 0 \\
\hline 17 & 48 & 0 & 0 & 0 & 0 & 0 & 9 & 0 & 0 \\
\hline 18 & 20 & $1-20$ & 0 & 2 & 0 & 0 & 4 & $5-10$ & $0-20$ \\
\hline 19 & 34 & 0 & 0 & 52 & $30-60$ & $2-50$ & 44 & $5-15$ & $0-5$ \\
\hline 20 & 61 & $10-40$ & 0 & 61 & $5-10$ & $0-5$ & 46 & $100-130$ & $80-90$ \\
\hline 21 & 90 & 1 & 0 & 11 & 0 & $0-5$ & 4 & $0-1$ & 5 \\
\hline 22 & 13 & 0 & 0 & 13 & $0-1$ & 0 & 8 & $0-20$ & 0 \\
\hline 23 & 54 & 5 & 1 & 19 & 0 & 0 & 0 & 30 & 60 \\
\hline 24 & 14 & 0 & 0 & 13 & 0 & 70 & 10 & 0 & $10-160$ \\
\hline 25 & 21 & 0 & 0 & 2 & 0 & $0-10$ & 2 & $\mathrm{NP}$ & $\mathrm{NP}$ \\
\hline 26 & 11 & $10-40$ & 0 & 13 & 0 & 0 & 24 & $50-60$ & 0 \\
\hline 27 & 11 & 0 & 0 & 17 & 0 & 0 & 10 & $1-20$ & 0 \\
\hline
\end{tabular}

BC, biochemical receptor assay (fmol/mg protein); epith, epithelial fraction; IHC, immunohistochemical receptor assay (histoscore); NP, not performed; Pt No, patient number; stroma, stromal fraction.

Oestrogen receptors were predominantly present in the epithelial fraction: the histoscore for oestrogen receptors in epithelium was positive in eight tumours. The epithelial oestrogen receptor histoscore did not correlate with the stromal score, but it did correlate with the ligand binding assay $(r=0.408, \mathrm{p}=0.03)$.

In two tumours the epithelial progesterone receptor status was positive; in one of these the stromal fraction was also positive. In three tumours only the stromal fraction was progesterone receptor positive. In four tumours progesterone receptor expression was heterogeneous: in some parts of the tumour a histoscore of 10 or more was found, while in other fractions the histoscore was 0 . The progesterone receptor histoscore did not correlate with the biochemical progesterone receptor value.

Immunohistochemistry showed that the epithelial fraction in seven of 26 tumours was androgen receptor positive; in three of these the stromal fraction was also positive. In two tumours only the stromal fraction was positive. In five tumours, androgen receptor expression was heterogeneous. The histoscores for androgen receptors in the epithelial and stromal fraction correlated positively $(r=0.741$, $\mathrm{p}<0.0005)$, while the epithelial androgen

Table 3 Receptor status in ovarian neoplasia

\begin{tabular}{|c|c|c|c|c|c|}
\hline & \multicolumn{3}{|c|}{ Biochemical analysis } & \multicolumn{2}{|c|}{$\begin{array}{l}\text { Immunohistochemical analysis } \\
\text { (epithelial fraction) }\end{array}$} \\
\hline & Negative & $\begin{array}{l}\text { Slightly } \\
\text { positive }\end{array}$ & Positive & Histoscore $\geqslant 10$ & Histoscore $\geqslant 35$ \\
\hline $\begin{array}{l}\text { Oestrogen receptor } \\
(\mathrm{n}=27)\end{array}$ & 1 & 9 & 17 & 8 & 3 \\
\hline $\begin{array}{l}\text { Progesterone receptor } \\
\quad(\mathrm{n}=27)\end{array}$ & 11 & 9 & 7 & 2 & 0 \\
\hline $\begin{array}{l}\text { Androgen receptor } \\
(\mathrm{n}=26)\end{array}$ & 14 & 12 & 0 & 7 & 3 \\
\hline
\end{tabular}

receptor histoscore correlated weakly with the ligand binding assay $(r=0.463, \mathrm{p}=0.03)$.

When the results of the biochemical and immunohistochemical methods were divided into positive and negative (table 1), no correlation was found between the receptor status of each steroid receptor and the method. The positive or negative status determined by one method was not associated with the positive or negative status determined by the other. This did not depend on the cut off level (histoscore $>10$, or $>35$ ) for positivity in the immunohistochemical method.

\section{Discussion}

A discrepancy was found between the steroid receptor status of ovarian neoplasia determined by biochemical and immunohistochemical detection methods. Only a weak correlation was found between the biochemical receptor assay and the epithelial histoscore for oestrogen receptors $(r=0.408, \mathrm{p}=0.03)$ and androgen receptors $(r=0.463, \mathrm{p}=0.03)$. There are several possible explanations for these discrepancies. ${ }^{410}{ }^{11}$ First, there may have been problems with sampling the tumour: heterogeneity of steroid receptor expression within a tumour always makes it uncertain whether the sample is representative of the whole tumour. When up to four samples of any one tumour were analysed by immunohistochemistry, the histoscore differed considerably in some cases. Receptor status was therefore positive in some parts and negative in other parts of the same tumour. This is in agreement with the theory of receptor heterogeneity. Second, the characteristics of a tumour may have played a role. It has been stated that the (benign) stromal fraction of a (malignant) tumour might be positive, while the epithelial fraction is negative This would result in false 
positive biochemistry results. ${ }^{11}$ Therefore the epithelial and stromal fraction were analysed separately. Oestrogen receptors were mainly expressed in the epithelial fraction, while both progesterone receptors and androgen receptors were expressed in both fractions, or in one or the other. Third, cytoplasmic receptors and receptors in the nuclei cannot be distinguished by the cytosol technique. In all the cases with positive staining of the nuclei, the cytoplasm was also stained. In some tumours, only the cytoplasm stained. We chose to disregard this for two reasons. First, it seems very unlikely that the leakage of receptor from the nucleus will lead to positive cytoplasm and completely negative nuclei, so when this was found, it was considered to be an artefact. Second, cytoplasmic staining also occurred in negative controls. Cytoplasmic staining in otherwise receptor negative tissues might be caused by endogenous peroxidase activity or non-specific binding of first antibody in the tissues.

The results obtained for oestrogen receptors and progesterone receptors with the biochemical method are in concordance with published reports. Sixty three per cent of the tumours were oestrogen receptor positive, compared with $30-64 \%$ in various reports. ${ }^{11}{ }^{15} 21-24$ Previous biochemical studies have shown that $28-67 \%$ of ovarian tumours are progesterone receptor positive. ${ }^{11}{ }^{152-24}$ In our study $59 \%$ of the tumours were progesterone receptor positive or slightly positive.

Surprisingly, according to the biochemical analyses none of the 26 tumours was androgen receptor positive, although 12 were slightly positive. The presence of androgen receptors has been investigated in only five studies in a total of 190 patients. In 132 (69\%) the (biochemical) receptor was positive. ${ }^{25}$ Kühnel et al used the same biochemical receptor assay on ovarian neoplasia and found that 85 of 95 ovarian carcinomas were androgen receptor positive. ${ }^{15}$ Another explanation for the discrepancy between our test results and published reports could be the characteristics of our study group. As our study was performed primarily to compare the biochemical and immunohistochemical steroid receptor status in ovarian neoplasia, we did not try to recruit a homogeneous group of patients. Therefore the receptor status was not related to the histology (type and differentiation) or staging of the tumour. Another possible explanation is that owing to the accumulation of genetic defects in the more poorly differentiated tumours, mutations occurred in androgen receptors that might have changed or disrupted the part of the protein that normally binds the antibody. In our immunohistochemical analyses we used an antibody that was selectively reactive with the $\mathrm{N}$-terminal domain of the androgen receptor.

When more than one specimen was available, the lowest histoscore was used. We did this is for several reasons. It should be realised that in a specimen with a histoscore of 10 , only a few cells stain positive for the receptor. Furthermore, the histoscore is a quantitative value that is not suitable for adding and dividing. Therefore the lowest, a median, or the highest score must be employed. For clinical purposes, for example the evaluation of tumour response to hormone treatment, theoretically the lowest score will be most representative of the tumour characteristics.

The histoscore used in this study to express oestrogen, progesterone, and androgen receptor status has been used for oestrogen receptor and progesterone receptor status in breast cancer, ${ }^{820}$ in endometrial carcinoma, ${ }^{5}$ and in ovarian carcinoma. ${ }^{12}$ A cut off value of 35 was employed for positivity in breast cancer in studies that compared immunohistochemistry with biochemistry. ${ }^{20}$ This has not been done for ovarian tumours. In our analyses, the control (breast cancer) specimens showed a higher intensity of staining than the ovarian samples. As these samples were all treated in the same way, differences in specimen handling could not have been responsible. In accordance with Grénman et al, the specimen was considered to be receptor positive when the histoscore was 10 or more. ${ }^{12}$ In table 3 results are given for two cut off levels (histoscore of $>10$ and > 35).

The small number of androgen receptor positive tumours on biochemical analysis is in agreement with the immunohistochemical analyses, in which seven of the 26 tumours were androgen receptor positive. Positive (prostate) and negative controls were analysed again and indicated adequate testing.

Our study is the second to report on immunohistochemical androgen receptor status in ovarian neoplasia and the first to use the histoscore. Chadha et al found that 23 of 32 primary ovarian malignancies were androgen receptor positive. ${ }^{10}$ Their semiquantitative method of scoring the receptor status consisted of two items: the level of immunostaining of tumour cells, and the percentage of androgen receptor positive cells in proportion to the total number of tumour cells. Positive and negative were not defined in their report. The discrepancy between their results and ours might reflect the different scoring systems. Chadha et al also used a different scoring system for immunohistochemical analyses of the progesterone receptor status: when $5 \%$ or more of the tumour cells were positive for progesterone receptor, the tumour was recorded as progesterone receptor positive. This was found in nine of the 27 tumours. Kommoss et al stated that $38 \%$ of their ovarian tumours were oestrogen receptor positive and $31 \%$ were progesterone receptor positive according to immunohistochemistry. ${ }^{11}$ Their scoring system and analyses were also different from ours, which makes comparison of the study results rather difficult.

Studies on steroid receptor status and the prognosis in ovarian carcinoma have yielded conflicting results. ${ }^{1122}{ }^{23}$ Immunohistochemical investigation of steroid receptors in ovarian carcinoma can tell us more about the evolution of these tumours. It is not known whether the primary tumour, metastases, and peritoneal implants all show similar expression of steroid receptors, or whether chemotherapy changes the biological function and presence of receptors in ovarian malignancies. Experience with 
hormone treatment for ovarian cancer shows that only $10 \%$ of the patients respond. ${ }^{26}$ It would be interesting to determine whether the response to hormone treatment depends on the presence and the distribution of steroid receptors.

CONCLUSIONS

The expression of androgen receptors in our study was very low compared with results in other published reports. Weak but significant correlations were found between the immunohistochemical and biochemical analyses of epithelial fraction oestrogen receptor and androgen receptor status. The histoscore varied considerably within several samples of the same tumour, which might explain the discrepancies between the immunohistochemical and biochemical results reported by us and other investigators. Oestrogen receptors were mostly found in the epithelial fraction, while progesterone and androgen receptors were also found in the stromal fraction. This will also have affected the correlation between the two analyses.

We are grateful to Dr P J Boodt, Dr Th J M Helmerhorst, Dr E M J Schutter, Mrs Dr J M Smits, and Dr W P Snijders for providing us with fresh ovarian tumour tissue. We are indebted to Mrs T C Linders for performing the radiochemical receptor assays and to Mrs T Tadema for her help with the immunohistochemical assays. We thank Dr A A Verstraeten for performing the statistical analyses and both him and Dr E J M performing the statistical analyses and both him and Dr E J M Schutter for their critical comments on a previous draft of the
manuscript. Dr H W Nijman participated in the study by writing the protocol and starting it up.

1 Stierer $\mathrm{M}$, Rosen $\mathrm{H}$, Weber $\mathrm{R}$, et al. Immunohistochemical and biochemical measurement of estrogen and progesterand biochemical measurement of estrogen and progesterone receptors

2 Molino A, Micciolo R, Turazza M, et al. Estrogen receptors in 699 primary breast cancers: a comparison of immunohistochemical and biochemical methods. Breast Cancer Res Treat 1995;34:221-8.

3 Nyholm HCJ, Nielsen AL, Lyndrup J, et al. Estrogen and progesterone receptors in endometrial carcinoma: Comparison of immunohistochemical and biochemical analysis. Int f Gynecol Pathol 1993,12:246-52.

4 Chambers JT, Carcangiu ML, Voynick IM, et al. Immunohistochemical evaluation of estrogen and progesterone receptor content in 183 patients with endometrial carcinoma. Part II. Correlations between biochemical and immunohistochemical methods and survival. Am $\mathcal{f}$ Clin Pathol 1990;94:255-60.

5 Grénman SE, Klemi P, Toikkanen S, et al. Association of steroid hormone receptor content and flow cytometric steroid hormone receptor content and flow cytometric DNA ploidy in

6 Aziz DC. Quantitation of estrogen and progesterone receptors by immunocytochemical and image analyses. $\mathrm{Am} \mathcal{F}$ Clin Pathol 1992;98:105-11.
7 Aasmundstad TA, Haugen OA, Johannesen E, et al. Oestrogen receptor analysis: correlation between enzyme immunoassay and immunohistochemical methods. F Clin Pathol 1992:45:125-9.

8 Bosman FT, Goeij AFPM de, Rousch M. Quality control in immunocytochemistry: Experiences with the oestrogen receptor assay. F Clin Pathol 1992;45:120-4.

9 Diest PJ, Weger DR, Lindholm J. Reproducibility of subjective immunoscoring of steroid receptors in breast cancer Anal Quant Cytol Histol 1996;18:351-4.

10 Chadha S, Roa BR, Slotman BJ, et al. An immunohistochemical evaluation of androgen and progesterone receptors in ovarian tumors. Hum Pathol 1993;24:90-5.

11 Kommoss F, Pfisterer J, Thome M, et al. Steroid receptors in ovarian carcinoma: immunohistochemical determination may lead to new aspects. Gynecol Oncol 1992;47:317-22.

12 Grénman SE, Klemi P, Toikkanen S, et al. Steroid hormone receptors and flow cytometric DNA ploidy in ovarian carcinoma. Ann Chir Gynaecol 1994;83:15-19.

13 Korsten CB, Persijn JP. Evaluation of and additional data on an improved simple charcoal method to determine oestrogen receptors. F Clin Chem Clin Biochem 1977;15:297-301.

14 Revision of the standards for the assessment of hormone receptors in human breast cancer; report of the second EORTC workshop, held on 16-17 march, 1979, in the Netherlands Cancer Institute. Eur f Cancer 1980;19:151315.

15 Kühnel R, Graaff J de, Rao BR, et al. Androgen receptor predominance in human ovarian carcinoma. $\mathcal{F}$ Steroid Biochem 1987;26:393-7.

16 Bradford MM. A rapid and sensitive method for the quantitation of microgram quantities of protein utilizing the principle of protein-dye binding. Anal Biochem 1976;72:24854.

17 Scatchard G. The attraction of proteins for small molecules and ions. Ann N Y Acad Sci 1949;51:660.

18 EORTC Breast Cancer Cooperative Group. Standards for the assessment of estrogen receptors in human breast cancer. Eur F Cancer 1973;9:379-81.

19 Koenders A, Thorpe SM. Standardization of steroid receptor assays in human breast cancer. IV. Long-term withinand between-laboratory variation of estrogen and progesterone receptor assays. Eur f Cancer Clin Oncol 1986;22: 945-52.

20 Scheres HME, Goei AFPM de, Rousch MJM, et al. Quantification of oestrogen receptors in breast cancer: radiochemical assay on cytosols and cryostat sections compared with semiquantitative immunocytochemical analysis. $\mathcal{F}$ Clin Pathol 1988;41:623-32.

21 Friedlander ML, Quinn MA, Fortune D, et al. The relationship of steroid receptor expression to nuclear DNA distribution and clinicopathological characteristics in epithelial ovarian tumors. Gynecol Oncol 1989;32:184-90.

22 Iversen OE, Skaarland E, Utaaker E. Steroid receptor content in human ovarian tumors: survival of patients with ovarian carcinoma related to steroid receptor content. Gynecol Oncol 1986;23:65-76.

23 Geyer H, Teufel G, de Gregorio G, et al. SteroidhormonRezeptoren beim Ovarialkarzinom und ihre Klinische Bedeutung. Onkologie 1984;7(suppl 2):44-52.

24 Lantta $M$. Estradiol and progesterone receptors in normal ovary and ovarian tumors. Acta Obstet Gynecol Scand 1984; 63:497-503.

25 Slotman BJ. Rationale for the use of endocrine therapy in ovarian cancer. Amsterdam: Free University, 1990. [Dissertation.]

26 Vange N van der, Greggi S, Burger CW, et al. Experience with hormonal therapy in advanced epithelial ovarian cancer. Acta Oncol 1995;34:813-20. 